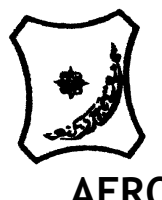

Bayero Journal of Pure and Applied Sciences, 11(1): 145 - 152

ISSN 2006 - 6996

\title{
AEROMAGNETIC DATA OVER KABO TOWN AND ITS ADJOINING AREAS, IN NORTHWESTERN NIGERIA
}

\author{
Suleiman ${ }^{\mathrm{a}}$, A., Aku $^{\mathrm{a}}$, M. O. and Sanusi ${ }^{\mathrm{b}}$, Y.A. \\ ${ }^{a}$ Department of Physics, Bayero University Kano, Nigeria. PMB 3011 \\ ${ }^{b}$ Department of Physics, Usmanu Danfodiyo University, PMB 2346, Sokoto. \\ *a Correspondence Author: abdullateefok@gmail.com, GSM: 08034617707
}

\section{ABSTRACT}

High resolution digital airborne data of sheet number 80 , and the geology of the study area were acquired from the Nigerian Geological Survey Agency (NGSA). The data were analyzed using upward continuation, tilt derivative and first vertical filters. The residual field of interest was obtained using the polynomial fitting technique and reduced to the magnetic equator to align the peaks of the anomalies with the centers of the source bodies. Application of the upward continuation filter to a vertical height of $2 \mathrm{~km}$ removed most of the very short wavelength anomalies emanating from very near-surface magnetized bodies and geologic noise, thereby enhancing the deeper bodies. The application of the tilt derivative highlighted areas of possible mineralization while the first vertical derivative filter shows lineaments along NE- SW, NW - SE and E - W major trends and NNE - SSW, WNW ESE and ENE - WSW minor trends. The trends of the inferred lineaments are generally consistent with those of the magnetic anomalies in the study area.

Key words: Upward continuation, Reduction to equator, Tilt Derivative, First Vertical Derivative, Basement Complex.

\section{INTRODUCTION}

Geophysics is a subject of natural science that is concerned with the physical processes and physical properties of the Earth and its surrounding space environment using the physics principles to the study of the earth's interior. It is therefore a three-fold application of the principles of Physics to the study of the Earth, Moon and Planets (Reynolds, 1997). Geophysics is applied to societal needs, such as mineral resources, mitigation of natural hazards and environmental protection. Geophysical survey data are used to analyze potential petroleum reservoirs, mineral deposits, locate groundwater and it also plays an essential role in the development of the theory of plate tectonics.

The Earth acts like a large spherical magnet: it is surrounded by a magnetic field that changes with time and location. The field is generated by a dipole magnet (i.e., a straight magnet with a North and South Pole) located at the center of the Earth. The magnetic fields of geological bodies are superimposed on the background of the Earth's main field. Variations in magnitude and direction of this field influence both the magnitudes and shapes of local anomalies. The purpose of magnetic surveying is to identify and describe regions of the earth's crust that have unusual (anomalous) magnetization. It can be carried out on land (ground survey), at sea (marine borne) and in air (air borne).

Aeromagnetic survey applications are extremely well known in a wide range of geological and exploration studies and they play an incredibly significant role in determining the lithological contacts, local and regional geological structures, faults, dykes, lineaments, delineation of mineral exploration targets, hydrocarbon reservoirs and their associated structures, depth to basement, crustal and tectonic studies. In this study, high resolution digital airborne data over Kabo and adjoining areas was employed in delineating subtle geological structures, their trends and possible exploration targets in the area.

Location and Geology of the Study Area

The area covered by this study is located approximately within latitudes $11^{\circ} 30^{\prime} \mathrm{N}$ to $12^{\circ} \mathrm{N}$ and longitudes $08^{\circ} \mathrm{E}$ to $8^{\circ} 30^{\prime} \mathrm{E}$ (Fig. 1). The area experiences a tropical climate having a rainy and a dry season. Rainy season begins in April/May and ends in October while dry season prevails for the rest of the year. The mean annual rainfall estimated by means of simple arithmetic method for 23 stations is about 785 $\mathrm{mm}$. Relative humidity at $10: 00 \mathrm{~h}$ varies from about 20 to 70\% (Federal Surveys, 1978). 


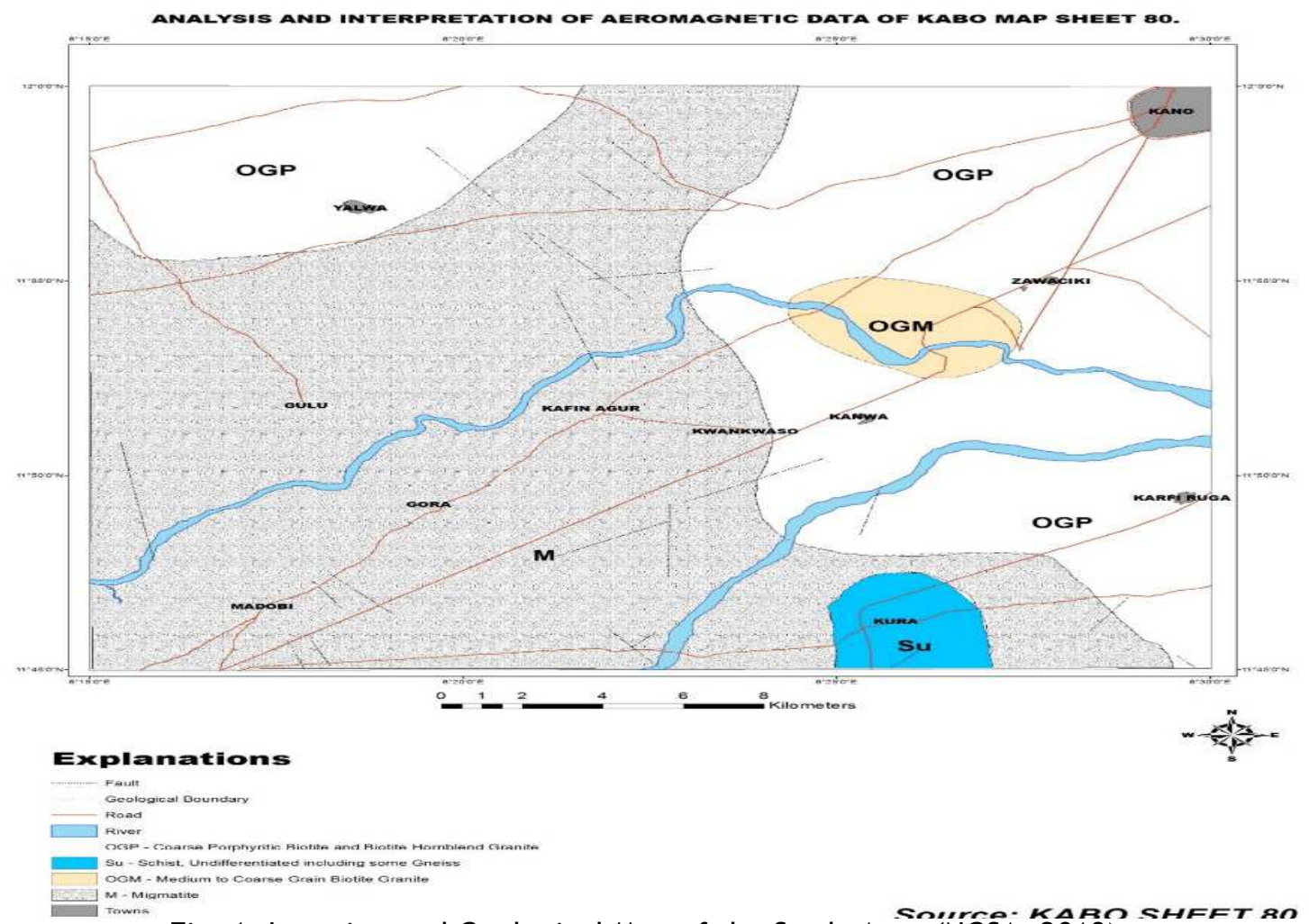

Fig. 1. Location and Geological Map of the Study Area (NǴSÂ, 2018).

The Northern Nigerian Basement Complex comprises three groups of rocks namely, migmatites and (high grade) gneisses derived from Birrimain sedimentary rocks through high grade metamorphism and granitization (Fig. 1); the Younger Metasediments of Upper Proterozoic age which are low grade metamorphic rocks were folded along with the migmatite and gneisses during the Pan-African orogeny; and the Older Granite series which were intruded during the Pan-African orogeny (Mccurry, 1989).

The surface geology (Fig. 2) shows granitegneiss suite, biotites-granites, migmatites and schists as exposed basement rocks in the study area. The migmatites are the predominant rocks in the western half with less dominant exposure of granite-gneiss in the northeastern part. The granite-gneiss are predominant in the eastern part where they were deformed and intruded in the central portion by the biotitegranites. Additionally, the apparent migmatites in the lower southeastern part were observed to be deformed and intruded by the schist rocks.

\section{MATERIALS AND METHODS}

\section{Aeromagnetic data Acquisition}

The data used for this research were high resolution digital airborne data obtained from the Nigerian Geological Survey Agency (NGSA). The aeromagnetic data were acquired by Fugro Airborne Surveys, on behalf of NGSA, as part of a nationwide aeromagnetic survey sponsored by the NGSA, along a series of NE - SW flight lines with a line spacing of $500 \mathrm{~m}$ and an average of $80 \mathrm{~m}$ terrain clearance. The geomagnetic gradient was removed from the data using the International Geomagnetic Reference Field (IGRF) model for 2005. This new data offers a lot of advantages in resolution and format over the old data (acquired in 1974) in which most of the earlier interpretations were made.

Regional - residual separation

To analyze the magnetic effects of the crustal rocks depicted as residual anomalies on the TMI map, the regional field intensity values representing the Earth's main field, were modelled in form of a plane surface and removed from the TMI values.

\section{Reduction to the equator}

One of the problems associated with interpretation of magnetic data is its dipolar nature, the effect of which causes the peaks of the anomalies to be skewed from the centre of the causative bodies. A phase-shift correction filter, known as reduction to equator (RTE), is often applied in the low latitude regions to ameliorate this effect. The filter is expressed as: 


$$
R T E=\sin I+i \cos I \sin (D-\theta)^{2}
$$

Where I is the geomagnetic inclination, $D$ is the geomagnetic declination, $\sin I$ is the amplitude component, $i \cos I \sin (D-\theta)^{2}$ is the phase component, and $\theta$ is the azimuthal angle.

The correction is normally accomplished in the frequency domain by multiplying the Fourier transformed data with the RTE filter and subsequently inverse Fourier transforming the product into the space domain. The Geosoft software Oasis Montaj (version 6.4) was used to perform the operation using a field strength of 34047.416, an inclination of 1.203 and declination of -1.3720 as basic inputs.

\section{Upward Continuation}

The method is a frequency domain based operation performed to estimate potential field data at a given height above which the data has been measured. The method is applied to enhance long wavelength anomalies associated with deep-seated structures at the expense of short wavelength anomalies associated with shallow bodies. The upward continuation filter is expressed as (Sanusi and Likkason, 2016)

$$
\begin{gathered}
\Delta T(x, y, z)=\sum_{n=0}^{n} \sum_{m=0}^{m} T(x, y, 0) \exp \left\{-2 \pi z\left(\frac{m^{2}}{L_{x}^{2}}\right.\right. \\
\left.\left.+\frac{n^{2}}{L_{y}^{2}}\right)^{\frac{1}{2}}\right\}
\end{gathered}
$$

Where $T(x, y, 0)$ is field measured at a horizontal plane $(\mathrm{z}=0), \mathrm{m}$ and $\mathrm{n}$ are wave numbers along $x$ and $y$ directions, $L_{x}$ and $L_{y}$ are fundamental wavelengths along $x$ and $y$ directions and $z$ is the height of continuation.

To estimate the upward continued field, the fast Fourier transformed magnetic data is multiplied with the upward continued filter in the frequency domain. The product is inverse fast Fourier transformed to the space domain to obtain the upward continued data.

\section{Tilt derivative}

The tilt derivative (TDR) is a filter employed in the frequency domain to enhance anomalies associated with shallow structures for mineral mapping. For high accuracy, the filter is applied after applying the RTE transformation. It is expressed as (Miller and Singh, 1994):

$$
T D R=\frac{\frac{\partial F}{\partial Z}}{\sqrt{\left(\frac{\partial F}{\partial x}\right)^{2}+\left(\frac{\partial F}{\partial y}\right)^{2}}}
$$

$\frac{\partial F}{\partial x}, \frac{\partial F}{\partial y}$ and $\frac{\partial F}{\partial z}$ are the derivatives of the RTE-RMI field along $x, y$ and $z$ directions. Also equation 3 hold, if and only if $F \neq 0$

The computation of the TDR filter is normally accomplished in the frequency domain with the computation of the derivatives and their subsequent substitution into equation (3).

The filter is multiplied by the Fourier transformed RTE-RMI data and the product is inversely transformed into the space domain to obtain the desired result. One of the most important properties of the TDR is that its anomalies are positive over the sources and negative as they move away from the sources.

First vertical derivative (FVD)

The first vertical derivative filter forms part of vertical filters often applied to enhance high frequency component of a magnetic data associated with shallow bodies at the expense of low frequency component associated with deep-seated bodies. It is usually estimated in the frequency domain, by multiplying the Fourier transformed data with the filter of the form $k^{n}$, where $\mathrm{k}$ is the wavenumber (Gunn, 1997).

\section{RESULTS AND DISCUSSION}

Total magnetic intensity (TMI) map

The TMI map of the study area (Fig. 2) is characterized by anomalies of high, intermediate and low value ranging between $33066.7 \mathrm{nT}$ to $32907.7 \mathrm{nT}$. The high values depicted in pink and red colours are predominant in the southern and extreme eastcentral parts and less dominant in the northern half of the area. The low values, depicted in light and dark blue colours, are more predominant in the eastern part and less dominant in the western part. The intermediate values, depicted in yellow and green colours, are more predominant in the western part and less dominant in the eastern part. The observed TMI anomalies are generally aligned along NE-SW, NW-SE and E-W directions. 


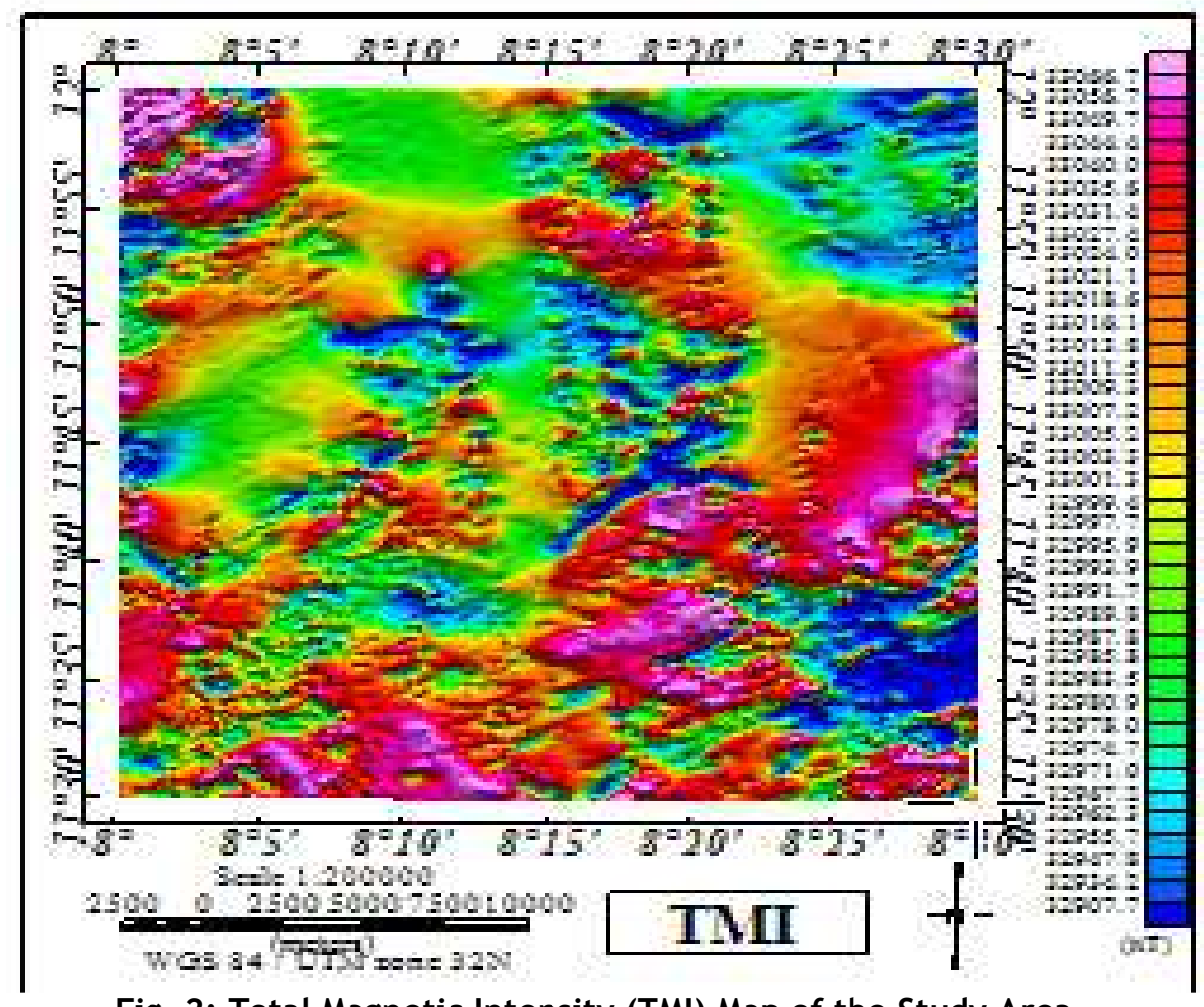

Fig. 2: Total Magnetic Intensity (TMI) Map of the Study Area

\section{Regional -Residual Separation (RRS)}

To analyze the magnetic effects of the crustal rocks, the regional magnetic field values, which represent the internal field from the earth's core, were modeled as a plane surface, using multi-regression analysis, and subtracted from the TMI values. In addition, the dipolar effects of the magnetic field were corrected by transforming the residual magnetic intensity (RMI) values to the magnetic equator, using reduction to equator (RTE) filter.

The RTE residual magnetic field map, shown in Figure 3, shows amplitudes varying from -74.4 to $59.7 \mathrm{nT}$, with positive amplitudes between $0.6 \mathrm{nT}$ to $59.7 \mathrm{nT}$ and negative amplitudes between -74.4 nT to $-1.0 \mathrm{nT}$. The positive amplitudes were observed to be dominant in the extreme west-central, east-central, southcentral and north-central parts of the area while the negative amplitudes are widespread throughout the study area. The high positive anomalies, depicted in red and pink colours, were interpreted as shallow highly magnetized intrusions and the negative anomalies as metamorphosed igneous rocks beneath the study area. Generally the high positive amplitude anomalies correlate with the migmatites, biotite-granites and the granitegneiss suites.

Upon removal of the effects of noise and very shallow magnetic bodies, which were manifested as short wavelength anomalies, from the RTE residual map, the upward continued map (Fig. 5) depicts smoother anomalies whose shapes and edges were better enhanced with amplitudes varying from -25.1 $\mathrm{nT}$ to $43.5 \mathrm{nT}$. Comparison between the RTEresidual and the upward continued maps shows two magnetic lows in the north-central part, which hitherto appeared as distinct anomalies on the RTE residual map, depicted as a single anomaly on the upward continued map. Thus, these two distinct bodies have coalesced into a single body in the subsurface. In addition, correlation between locations of magnetic highs on both maps suggests subsurface continuation of the highly magnetized intrusives beneath the area. The trends of the upward continued anomalies are aligned along NE-SW, NW-SE, E-W and NNW-SSE directions, suggesting that the NNW-SSE trending anomalies were hitherto masked by short wavelength anomalies on the RTE- residual map. 


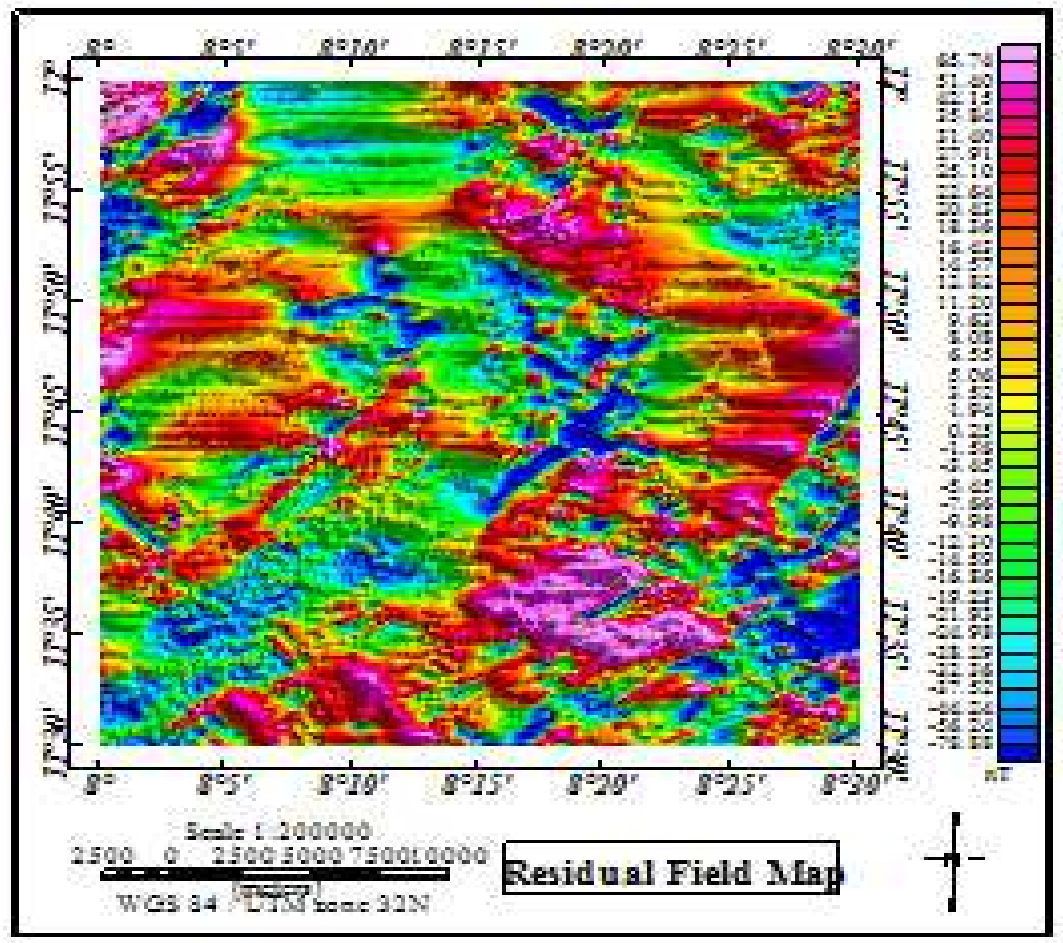

Fig.3: Residual Field Map of the Study Area

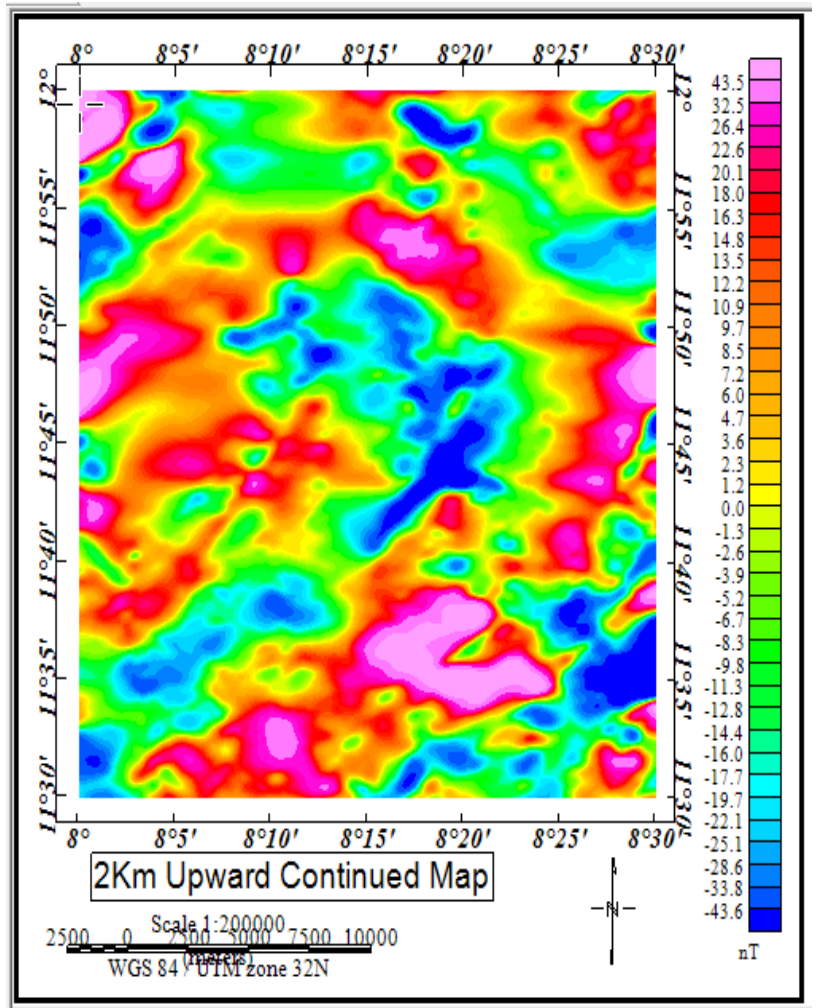

Fig.4: Reduction to the Equator Map of the Study Area.

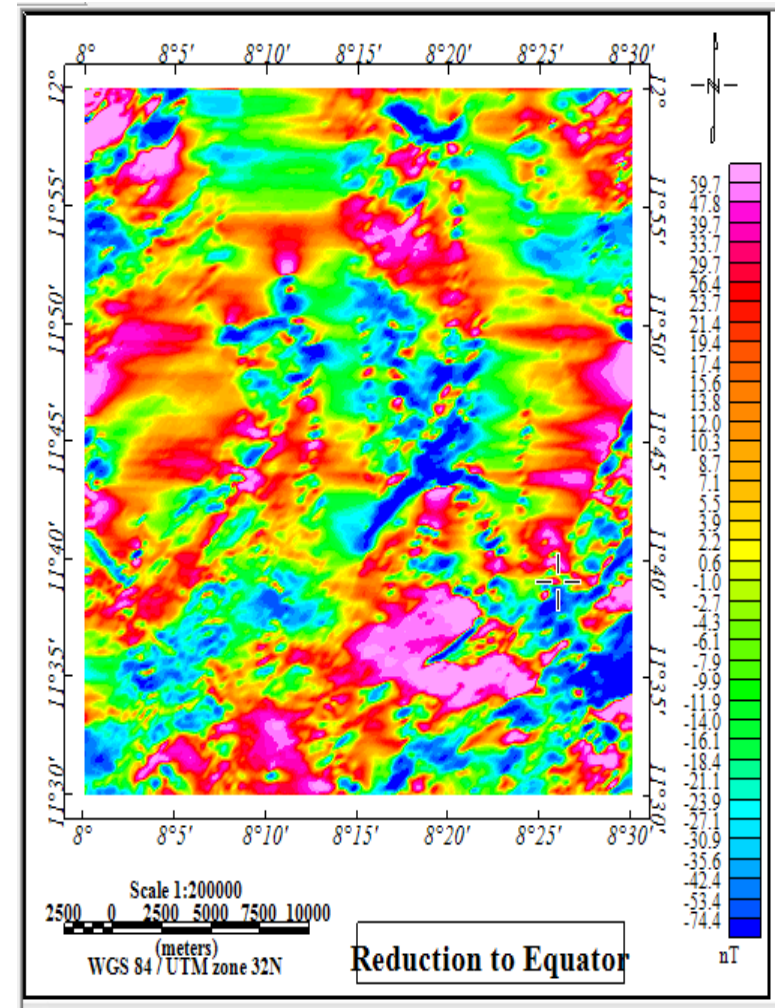

Fig.5: $2 \mathrm{~km}$ Upward Continued Map of the Study Area. 
First Vertical Derivative Result (FVD)

The FVD map fig. 6 shows anomalies with amplitudes varying between -0.0388 and 0.0316 . The high amplitude anomalies, depicted in red and pink colours, are wide spread, however, with dominance in the southern half than in the northern half. However, the low and intermediate amplitude anomalies, depicted in yellow, green and blue colours are widespread without noticeable dominance. Similar to the TDR map, the anomalies are both linear and curvilinear in shape. The curvilinear and the NE-SW trending anomalies earlier inferred in the TDR are also apparent on the FVD map.

To analyze the subsurface lineaments beneath the study area, contact positions depicted as dots, were delineated and superposed on the FVD map, using the method of Blakely and Simpson (1986).

Analysis of the trends of the inferred lineaments, shown in Figure 7, shows NE- SW, NW - SE and E - W as predominant or major trends and the NNE - SSW, WNW - ESE and ENE WSW as less predominant or minor trends. The different orientations of these inferred lineaments suggest that the study area has been affected by different stress regimes at different geologic phases. The oldest orogeny recorded in the basement complex of Nigeria is the Liberian (> $2500 \mathrm{ma}$ ) and is characterized by $\mathrm{E}$ - W lineaments.

The Pan African orogeny (650 ma $\pm 150 \mathrm{ma}$ ), associated with a thermoremnant event, is characterized by conjugate NE - SW and NW SE lineaments (Genik, 1992). The presence of the inferred lineament trends in the study area, as revealed by the present study, suggests imprints of the Liberian and African orogenies in the study area. Following Oladunjoye et al. (2016), the thermal effects of the emplacement of the basement rocks whose epeirogenesis is associated with the Pan African events may be possible cause of the curvilinear lineament observed in northern part of the study area. Finally, the lineament trends inferred in this study are consistent with the trends inferred from previous studies in the northern Nigerian basement complex (Olasehinde et al., 1990; Raimi et al., 2014; Salau et al., 2016).

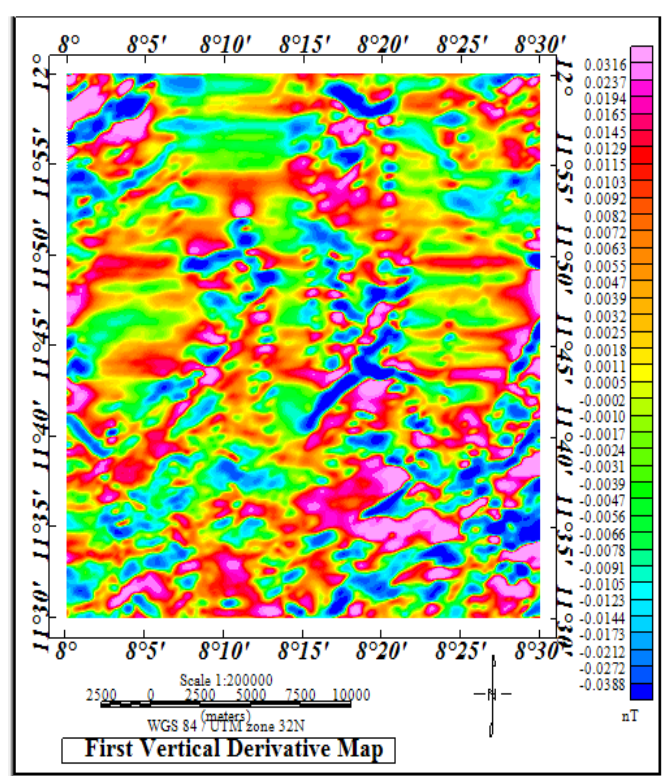

Fig. 6: First Vertical Derivative Map of the Study Area. subsurface lineaments

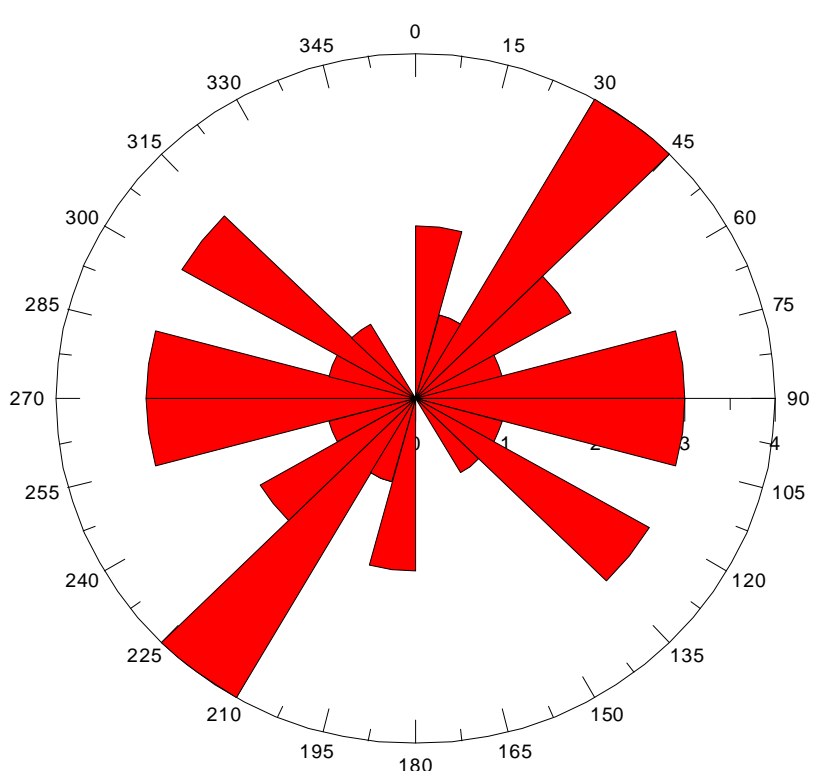

Fig. 7: Trends of the inferred 

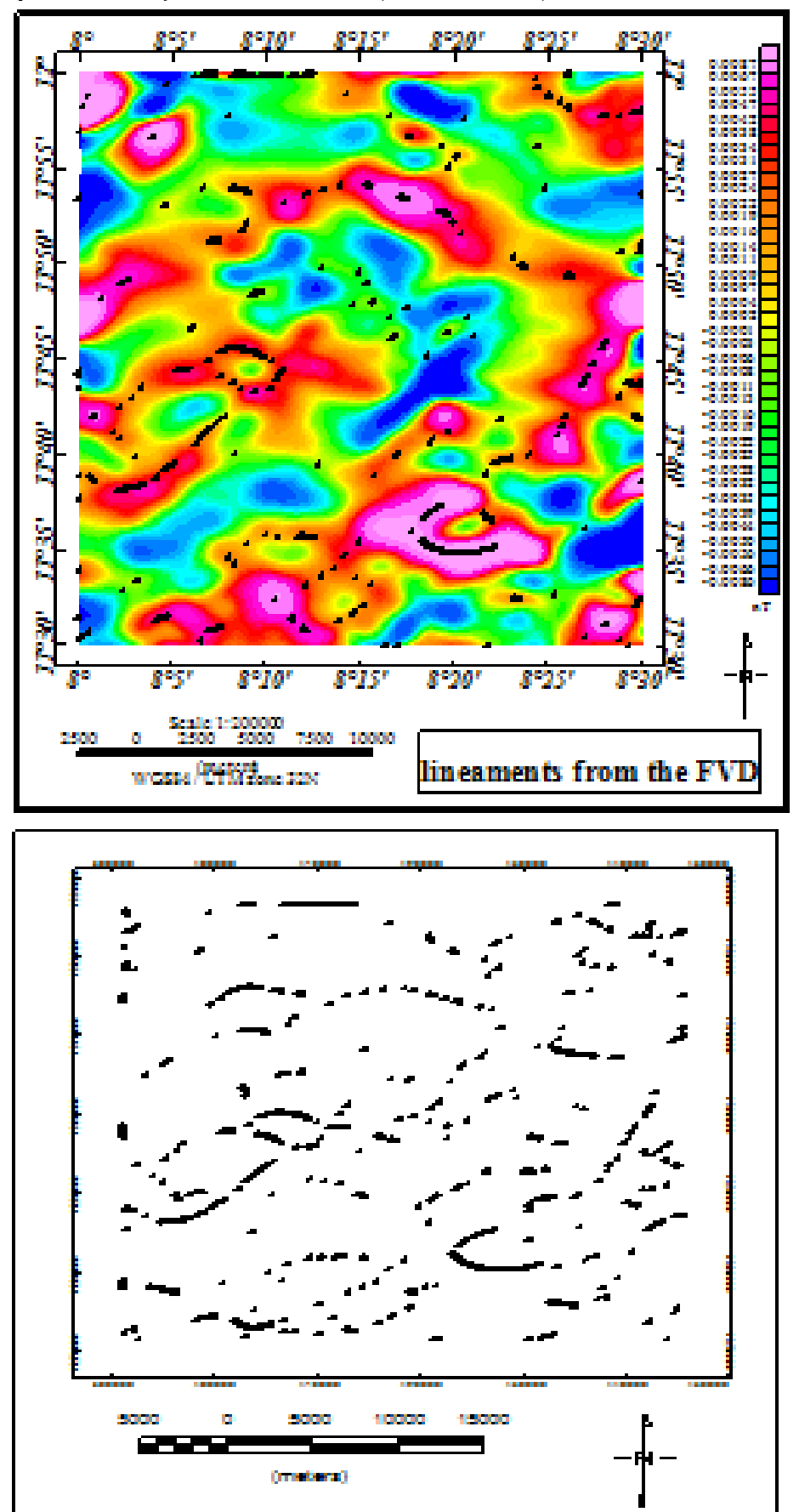

Fig. 8: Lineaments from the FVD Map of the Study Area

Tilt Derivative Result (TDR)

The TDR map obtained from the upward continued RTE-RMI field (Fig 9) shows anomalies associated with amplitudes ranging from -1.344 $\mathrm{nT} / \mathrm{km}$ to $1.334 \mathrm{nT} / \mathrm{km}$. Notably, both the high and low amplitude anomalies are widespread throughout the study area, with the high amplitudes apparently superposed on the low amplitudes. Furthermore, the TDR anomalies, which are linear and curvilinear in shape, appear thinner and sharper than those apparent on the upward continued map. Thus, the edges of the anomalies are better enhanced with the application of the TDR filter than the upward continued filter. A curvilinear positive anomaly cutting across the northern half and a NE-SW trending anomaly cutting across the SE and SW parts both of high amplitudes were observed. These lineaments were interpreted as possible mineral exploration targets with minerals of high magnetic content, such as magnetite and illemanites. The trends of the TDR anomalies are generally along NE-SW, NW-SE, E-W and NNW-SSE directions, which is consistent with the trends of the anomalies apparent on the RTE-RMI and upward continued maps. 


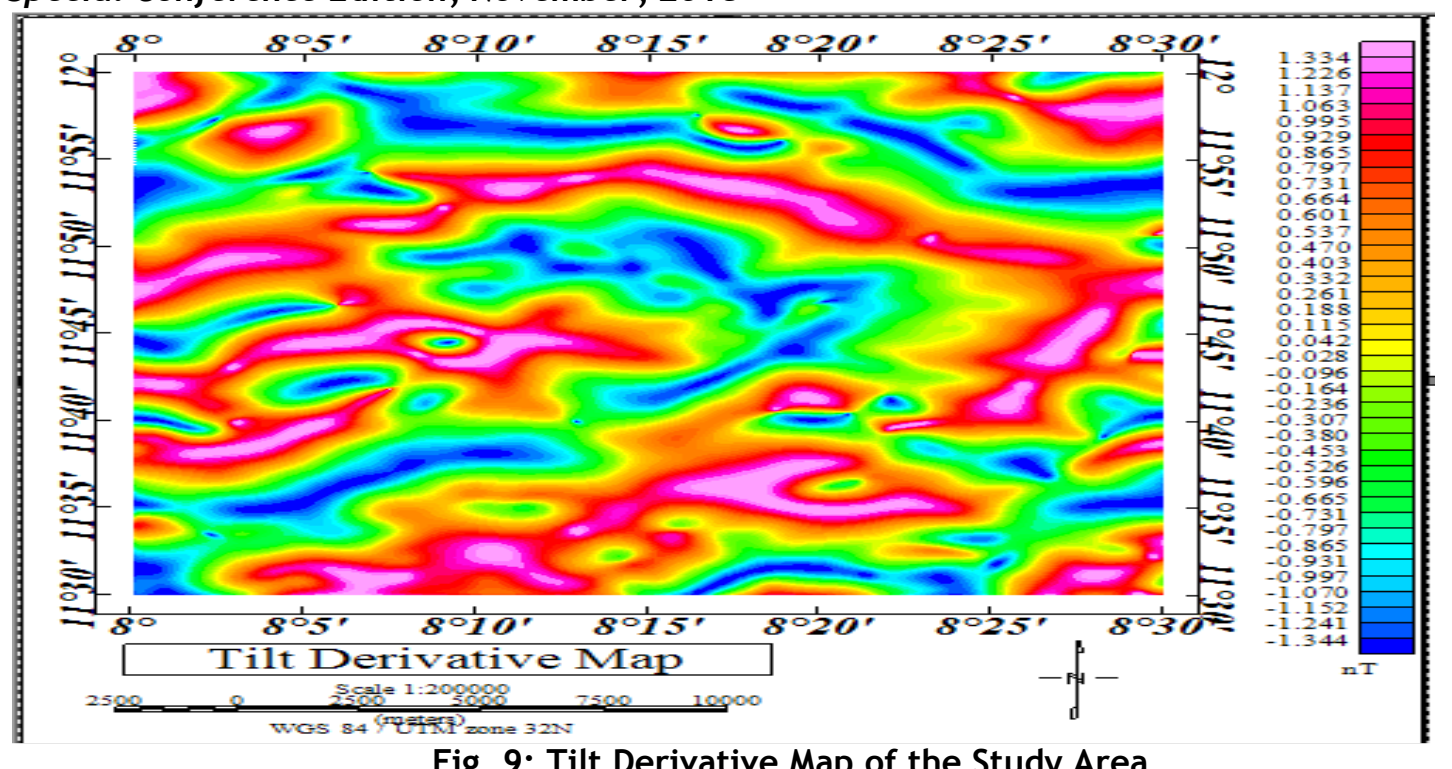

\section{CONCLUSION}

High resolution aeromagnetic data over Kabo and its adjoining areas were acquired and analyzed using upward continuation, tilt derivative and first vertical derivative methods. Based on the results obtained, the following conclusions were drawn

(1) The basement rocks of the area were deformed and affected by different stress regimes at different geologic phases

\section{REFERENCES}

Blakely, R. J. and Simpson, R. W. (1986). Approximating edges of source bodies from magnetic or gravity anomalies. Geophysics, 51, $1494-1498$.

Federal Surveys 1978. The National Atlas of the Federal Republic of Nigeria. Federal Surveys of Nigeria, First Edition, p. 136.

Genik, G.J. 1992. Regional framework and structural aspects of rift basins in Niger, Chad and the Central African Republic: P.A. Zeigler (Editor), Geodynamics of Rifting, Volume II. Case History Studies on Rifts: North and South America and Africa. Tectonophysics, 213: 169185.

Gunn, P. J. 1997. Application of aeromagnetic surveys to sedimentary basin studies. Australian Geological Society Organisation (AGSO) Journal of Australian Geology and Geophysics, Vol. 17, No. 2, Pp. 133-144.

Mccurry P 1989.A general review of the geology of the Precambrianto Lower Palaeozoic rocks of northern Nigeria. In: Kogbe, C. A. (ed) Geology of Nigeria, 2nd Ed., Rock View (Nigeria) Limited.

Miller, H. G. and Singh, V. (1994). Potential Field Tilt a New Concept for location of potential Field Sources. Journal of Applied Geophysics, 32, 213-217.

Nigerian Geological Survey Agency (NGSA), 2018. Location and Geological Map of the Study Area.
(2) The basement rocks were structurally controlled by lineaments trending along NE-SW, NW-SE and E-W major directions and NNE-SSW, WNW- ESE and ENE- WSW minor directions.

(3) The imprints of Liberian and PanAfrican orogenies are manifested in the study area.

(4) The study area has a high potential of mineralization.

Oladunjoye, M. A., Olayinka, A. I., Alaba, M. and Adabanija, A. M. (2016). Interpretation of high resolution aeromagnetic data for lineaments study and occurrence of banded iron formation in Ogbomoso area, Southwestern Nigeria. Journal of African Earth Sciences, 114, 43-53.

Olasehinde, P. I., Pal, P. C. and and Annor, A. E. (1990). Aeromagnetic anomalies and structural lineaments in the Nigerian basement complex. Journal of African Earth Sciences, 3(4): 351 - 355.

Raimi, J., Dewu, B. B. M. and Sule, P. (2014). An interpretation of structures from the aeromagnetic field over a region in the Nigerian Younger Granite Province. International Journal of Geosciences, 5: 313 323.

Reynolds, J. M. 1997. An Introduction to Applied and Environmental Geophysics. John Wiley and Sons Ltd.

Salau, S. I., Danbatta, U. A. and Agunleti, Y. S. (2016). The interpretation of aeromagnetic and satellite imagery for structures coincident with Gold mineralization in Anka Schist Belt, Northwestern Nigeria. Journal of Applied Geology and Geophysics ( IOSR-JAGG), 4 (5): $29-34$.

Sanusi, Y. A. and Likkason, O. K. (2016). Angular spectral analysis and lowpass filtering of aeromagnetic data over western part of Bornu basin of Nigeria. Nigerian Journal of Basic and Applied Science, 24(2), 73 - 84. 